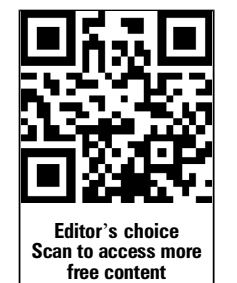

free content

- Additional material is published online only. To view please visit the journal online (http://dx.doi.org/10.1136/jech2013-203555).

For numbered affiliations see end of article.

\section{Correspondence to}

Dr Sari Stenholm, Department of Public Health, University of Turku, Fl-20014 Turun yliopisto, Finland; sari.stenholm@thl.fi

Received 23 October 2013 Revised 16 December 2013 Accepted 27 January 2014 Published Online First 17 February 2014

\section{SLinked}

- http://dx.doi.org/10.1136/ jech-2014-203945

CrossMark

To cite: Stenholm $S$ Westerlund H, Salo P, et al. J Epidemiol Community Health 2014;68:503-509.

\title{
Age-related trajectories of physical functioning in work and retirement: the role of sociodemographic factors, lifestyle and disease
}

\author{
Sari Stenholm, ${ }^{1,2}$ Hugo Westerlund, ${ }^{3}$ Paula Salo, ${ }^{4,5}$ Martin Hyde, ${ }^{3}$ Jaana Pentti, ${ }^{4}$ \\ Jenny Head, ${ }^{6}$ Mika Kivimäki, ${ }^{4,6}$ Jussi Vahtera ${ }^{1,4,7}$
}

ABSTRACT

Background Loss of physical functioning is an early marker of declining health in older people. The objective of this study was to examine the age-related trajectories of physical functioning among those in full-time work and retirement.

Methods Based on the Health and Retirement Study, participants who were working full-time or were in fulltime retirement and $65-85$ years of age during the follow-up period from 1992 to 2010 were included ( $n=17844$, $n$ of observations from repeated measures in full-time work 5891 and in retirement 57 117). Details of physical functioning were asked about at all study phases and 10 items related to mobility and activities of daily living were summed to obtain a physical

functioning score (0-10).

Results The number of physical functioning difficulties increased every 10 years by 0.17 ( $95 \% \mathrm{Cl} 0.04$ to 0.29 ) when in full-time work and by $0.46(95 \% \mathrm{Cl} 0.41$ to 0.50 ) in retirement after adjusting for age, sex, race, education, total wealth, Body Mass Index, smoking, physical activity and number of diseases. Factors that were associated with a significantly greater increase in number of physical functioning difficulties in full-time work and retirement include lifestyle-related risks and chronic conditions.

Conclusions Physical functioning declines faster in retirement than in full-time work in employees aged 65 years or older and the difference is not explained by absence of chronic diseases and lifestyle-related risks.

\section{INTRODUCTION}

In most of the industrialised world, the workforce is ageing due to changes in global age profiles. In the USA, the current average old age pension age is 65 years and 8 months, but it will gradually rise to 67 years by the year $2027 .{ }^{1}$ Despite the fact that current cohorts of older adults are healthier today than ever before, the possibility of diseases, and physical and mental limitations, increases with advancing age. Loss of physical functioning is an early marker of declining health and in time it also seriously threatens the independence and quality of life of older people. ${ }^{2}$ Persons with functional limitation are less likely to remain active in the community, will need more social and healthcare services and have higher rates of mortality. ${ }^{3}$ During the past three decades, researchers have investigated the predictors of functional decline, including socioeconomic position, lifestyle factors and chronic diseases. ${ }^{5} 6$ One important, but less examined, factor associated with health and functional outcomes later in life is work status.

Earlier prospective studies have shown that among people aged 60 years and older, productive engagement such as paid work, voluntary work and caregiving is associated with less physical disability as well as better cognitive functioning and self-rated health. ${ }^{7-9}$ On the other hand, other studies suggest that retirement may have beneficial effects on physical and mental health. ${ }^{10}{ }^{11}$ A recent study by Jokela et $a l^{12}$ based on the Whitehall II cohort study of British civil servants found that statutory retirement at age 60 was associated with a more favourable trajectory of physical functioning compared with being in the workforce after the age of 60 . They also found that retired civil servants aged 60 years had the same level of physical functioning as the non-retired counterparts at age 58 . No previous study has examined how trajectories of physical functioning differ as a function of age and by working status among people aged $65-86$ years. It is also unknown if remaining in the work will maintain physical function even in very old age when individuals may have developed chronic conditions.

The Health and Retirement Study (HRS) is a longitudinal cohort study of retirement and health among the elderly in the USA. The extraordinarily rich and complex data with repeated measurements provide an opportunity to examine the trajectories of physical functioning across age groups and whether the trajectories are different when in fulltime work and retirement. We also examined the association of sociodemographic characteristics, lifestyle factors and chronic diseases with physical functioning trajectories in full-time work and retirement.

\section{METHODS \\ Participants}

The HRS is an ongoing cohort study consisting of Americans over the age 50, with interview data collected biennially on demographics, health behaviour, health status, employment, income and wealth, and insurance. The first cohort was interviewed in 1992 and subsequently every 2 years and five additional cohorts have been included in the study phases between 1994 and 2010. The full details of the study are described elsewhere. ${ }^{13}$ Ethical approval for the HRS Study was obtained from the University of Michigan Institutional Review Board. 
In this study, we used data from 1992 to 2010. Of all 29655 participants, we included participants who were 65-85 years of age at any study phase and had information on physical functioning from at least one study phase $(n=19$ 906). For the purpose of this study, we focused on two distinct statuses: working full-time and retired. Thus, those who reported being at part-time work, unemployed, partly retired, disabled or not in the labour force at any study phase were excluded. These selection criteria resulted in a sample of 17844 participants (8311 men and 9533 women); of these, 1399 were still in fulltime work at the end of their follow-up, 15092 had already retired and 1353 moved from full-time work to retirement during the follow-up. In total, 63008 observations (5891 in full-time work and 57117 in retirement) were used in the analyses. Average length of follow-up was 5.6 years ranging from 0 to 18 years. The participants participated on average in four study phases, which range from 1 to 10 .

\section{Measurement of physical functioning}

Physical functioning relevant for daily activities was asked about at all phases using standardised instruments. Difficulties in mobility, arm functions and fine-tuned motor function were selfassessed on 10 tasks: walking one block, sitting for about $2 \mathrm{~h}$, getting up from a chair after sitting for long periods, climbing several flights of stairs without resting, climbing one flight of stairs without resting, stooping, kneeling or crouching, reaching or extending arms above shoulder level, pulling or pushing large objects (like a living room chair), lifting or carrying weights over $5 \mathrm{~kg}$ (like a heavy bag of groceries), and picking up a small coin from a table. Subjects who reported that they had difficulty or were unable to do the task were coded as having difficulty with the task (yes/no). These 10 items were summed to obtain a physical functioning score, with higher scores indicating more severe limitations (range 0-10). This composite measure has been used in previous large scale studies ${ }^{14}{ }^{15}$ and the advantage is that it allows us to assess a broad range of physical functioning simultaneously. ${ }^{16}$ 17-19

\section{Measurement of working status}

At each study phase, the participants reported their labour force status with the following options: working full-time, working part-time, unemployed, partly retired, retired, disabled or not in the labour force. For the purpose of this study, we focused on two distinct statuses, working full-time and retired.

\section{Covariates}

Three time-invariant variables were included: gender, race and education. Race was categorised into three groups (White/ Caucasian, Black/African American and Other). Education was categorised at three levels (low=less than high school; medium=high school or some college; and high=college and above). Other variables were used as time-variant since these could change across study phases. Non-housing financial wealth was divided into tertiles (low, less than \$3000; middle, \$300055 000; and high, more than $\$ 55000$ ). Health insurance coverage (yes/no) was defined based on information on whether or not the participant was covered through federal government health insurance programme, current or previous employer or any other health insurance.

Smoking status was defined as no, ex-smoker and current smoker. Body Mass Index (BMI) was calculated using reported height and weight, and categorised as normal weight BMI 18.5$24.9 \mathrm{~kg} / \mathrm{m}^{2}$, overweight BMI $25-29.9 \mathrm{~kg} / \mathrm{m}^{2}$ and obese $\mathrm{BMI} \geq 30 \mathrm{~kg} / \mathrm{m}^{2}$. Low physical activity was defined as less than three activity sessions per week. Number of lifestyle-related risks (current smoking, obesity and low physical activity) was calculated and categorised as 0, 1 and 2 or more.

Chronic diseases were determined in each study phase by asking respondents: 'Has a doctor ever told you that you have...?' Six chronic diseases, suggested by their significant association with physical functioning, were included: (1) heart disease (heart attack, coronary heart disease, angina, congestive heart failure or other heart problems), (2) stroke (stroke or transient ischaemic attack), (3) chronic lung disease (chronic bronchitis or emphysema), (4) cancer (cancer or a malignant tumour of any kind except skin cancer), (5) diabetes (diabetes or high blood sugar) and (6) arthritis (arthritis or rheumatism). Number of chronic conditions was calculated and categorised as 0,1 and 2 or more.

\section{Statistical analysis}

Study population characteristics are reported across study phases by working status and age group as mean values for continuous variables and proportions for categorical variables. Age-dependent physical functioning trajectories associated with working status were assessed using linear regression analyses with generalised estimation equations controlling for the intraindividual correlation between repeated measurements using an exchangeable correlation structure. ${ }^{17}{ }^{18}$ In these models, data are structured so that measurement times (observations) are nested within participants. On average, participants provided data at four of the possible 10 study phases (range 1-10). Thus, based on their working status, participants contributed to physical functioning calculations in full-time work and/or retirement.

To examine whether the age-related trajectories were dependent on working status, we tested working status $\times$ age interaction effects. Age represents the time variable in the model and was determined by the respondent's age at each interview phase. To examine the linearity of the trajectories with increasing age, we introduced age square in the model. The age $\times$ age term was not statistically significant $(p=0.19)$, and thus a linear term was fitted for continuous age. In the analyses, we examined the differences in the level and trajectories of physical functioning among participants in full-time work and retirement. In addition, the differences according to sociodemographic characteristics, lifestyle factors and chronic diseases were also studied. Since there were significant differences in physical functioning among full-time workers and retirees, further analyses were conducted separately by working status. Adjusted mean estimates were calculated to represent average level and trajectories of physical functioning among full-time workers and retirees and by sociodemographic factors as well as by lifestyles and disease subgroups. Interactions for age $\times$ sex, age $\times$ race, age $\times$ education, age $\times$ wealth, age $\times$ number of lifestyle-related risks and age $\times$ number of chronic conditions were examined separately and the models were additionally adjusted for sociodemographic factors (sex, race, education, non-housing financial wealth and health insurance coverage), lifestyle factors (smoking, BMI, physical activity), number of chronic conditions as well as for the study cohort. The values for time-varying covariates (wealth, health insurance, smoking, BMI, physical activity and number of chronic conditions) were taken from the previous time point as the outcome variable (physical functioning).

To address the possibility that including those who moved from full-time work to retirement during the follow-up may have confounded the results because of the selection due to poor health, we repeated the main analysis by taking into account only those who remained in the same work status 
Table 1 Characteristics of study population according to age groups and working status across study phases: Health and Retirement Study (n of observations 63008 )

\begin{tabular}{|c|c|c|c|c|c|c|c|c|}
\hline & \multicolumn{4}{|c|}{ Full-time work ( $\mathrm{N}=5891)$} & \multicolumn{4}{|c|}{ Retired ( $N=57$ 117) } \\
\hline & $65-69$ & $70-74$ & $75-79$ & $80-85$ & $65-69$ & $70-74$ & $75-79$ & $80-85$ \\
\hline$n$ & 3708 & 1464 & 532 & 187 & 14103 & 15892 & 14612 & 12510 \\
\hline Men, \% & 61.5 & 64.8 & 71.1 & 73.8 & 47.9 & 47.0 & 46.9 & 45.1 \\
\hline \multicolumn{9}{|l|}{ Race, \% } \\
\hline White & 81.2 & 84.4 & 87.0 & 90.9 & 81.1 & 83.1 & 84.6 & 85.8 \\
\hline Black & 14.2 & 12.7 & 10.7 & 9.1 & 15.5 & 13.8 & 12.6 & 11.7 \\
\hline Other & 4.6 & 2.9 & 2.3 & 0.0 & 3.4 & 3.1 & 2.9 & 2.5 \\
\hline \multicolumn{9}{|l|}{ Education, \% } \\
\hline Less than high school & 22.7 & 24.7 & 26.7 & 31.6 & 31.3 & 32.1 & 33.8 & 36.4 \\
\hline High school & 50.2 & 49.9 & 52.8 & 43.9 & 52.4 & 51.6 & 50.3 & 48.7 \\
\hline College and above & 27.1 & 25.4 & 20.5 & 24.6 & 16.3 & 16.3 & 15.9 & 15.0 \\
\hline \multicolumn{9}{|l|}{ Non-housing financial wealth, $\%$} \\
\hline Lowest tertile & 35.5 & 33.4 & 30.3 & 19.2 & 36.9 & 34.0 & 32.2 & 29.4 \\
\hline Middle tertile & 36.6 & 35.0 & 35.2 & 33.5 & 32.5 & 33.4 & 33.2 & 33.6 \\
\hline Highest tertile & 27.8 & 31.6 & 34.5 & 47.3 & 30.6 & 32.6 & 34.6 & 36.9 \\
\hline Covered by health insurance, $\%$ & 85.8 & 97.3 & 98.1 & 98.2 & 85.5 & 98.9 & 99.4 & 99.5 \\
\hline \multicolumn{9}{|l|}{ Body Mass Index, \% } \\
\hline Normal weight & 27.6 & 31.1 & 31.4 & 41.0 & 29.4 & 32.6 & 37.4 & 46.2 \\
\hline Overweight & 42.9 & 43.4 & 46.5 & 43.2 & 40.7 & 40.7 & 41.2 & 38.7 \\
\hline Obese & 29.5 & 25.5 & 22.2 & 15.9 & 29.9 & 26.7 & 21.4 & 15.1 \\
\hline \multicolumn{9}{|l|}{ Smoking, \% } \\
\hline Never smoker & 40.8 & 40.5 & 40.3 & 43.2 & 35.1 & 37.6 & 39.6 & 43.8 \\
\hline Ex-smoker & 45.8 & 49.0 & 49.5 & 51.4 & 48.1 & 50.1 & 51.5 & 50.4 \\
\hline Current smoker & 13.4 & 10.5 & 10.2 & 5.4 & 16.8 & 12.3 & 9.0 & 5.8 \\
\hline Low physical activity, \% & 62.5 & 63.1 & 61.2 & 64.3 & 67.0 & 70.0 & 72.8 & 78.9 \\
\hline \multicolumn{9}{|l|}{ Number of lifestyle-related risks, $\%$} \\
\hline 0 & 25.8 & 30.1 & 32.7 & 36.4 & 23.2 & 26.2 & 26.2 & 23.2 \\
\hline 1 & 46.1 & 46.5 & 47.7 & 47.6 & 44.5 & 47.0 & 52.0 & 60.9 \\
\hline 2 or more & 28.1 & 23.4 & 19.6 & 16.0 & 32.3 & 26.8 & 21.7 & 15.9 \\
\hline \multicolumn{9}{|l|}{ Number of diseases, $\%$} \\
\hline 0 & 34.1 & 30.8 & 30.8 & 24.1 & 21.3 & 20.4 & 17.5 & 15.2 \\
\hline 1 & 41.9 & 40.1 & 34.8 & 41.2 & 38.8 & 36.5 & 35.0 & 33.1 \\
\hline 2 or more & 24.0 & 29.1 & 34.4 & 34.8 & 39.9 & 43.1 & 47.5 & 51.7 \\
\hline
\end{tabular}

group (ie, full-time work or retired) during the entire follow-up. The SAS V.9.3 Statistical Package was used for all analyses (SAS Institute Inc., Cary, North Carolina, USA).

\section{RESULTS}

Data from 17844 individuals comprised 63008 observations (5891 in full-time work and 57117 in retirement). Table 1 shows characteristics of study population by working status and age group. The average age in the full-time work group was 69.2 (SD 4.2) years and retirement 74.3 (SD 5.7) years. More men continued working full-time after the age of 65 than women $(64 \%$ vs $36 \%)$, whereas during retirement the gender distribution was more equal (47\% vs 53\%). Participants in fulltime work had more often college level education $(26 \%$ vs $16 \%)$ than retirees. Number of chronic conditions increased with age and retirees had more often two or more diseases than full-time workers ( $45 \%$ vs $27 \%$ ).

Figure 1 shows number of physical functioning difficulties by working status in different age groups. Number of physical functioning difficulties was higher with increasing age, but the increase was significantly smaller during years in full-time work than in retirement (test of interaction $p=0.002$ ). The number of physical functioning difficulties increased per every 10 years increase in age by 0.49 (95\% CI 0.31 to 0.67$)$ when in full-time work and by 0.63 (95\% CI 0.54 to 0.72 ) in retirement after adjusting for sex, race, education, non-housing wealth, health insurance coverage, BMI, smoking, physical activity, number of diseases and study cohort (table 2).

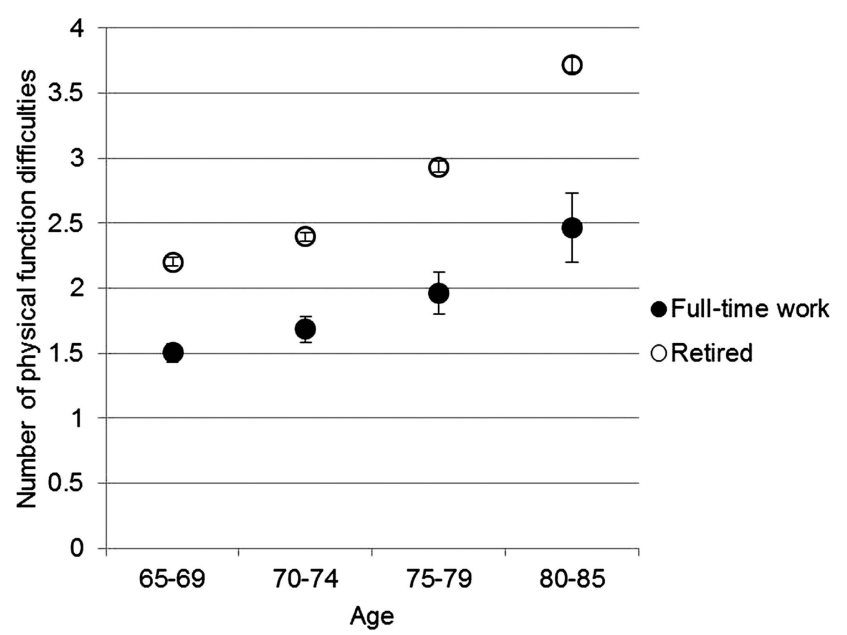

Figure 1 Number of physical functioning difficulties according to age and working status. 
Table 2 Average level and 10-year change at population level in number of physical functioning difficulties according to sex, race, education and non-housing financial wealth

\begin{tabular}{|c|c|c|c|c|c|c|c|c|}
\hline & \multicolumn{4}{|l|}{ Full-time work } & \multicolumn{4}{|l|}{ Retired } \\
\hline & Average level* & $95 \% \mathrm{Cl}$ & 10-year change $\dagger$ & $95 \% \mathrm{Cl}$ & Average level* & $95 \% \mathrm{Cl}$ & 10-year changet & $95 \% \mathrm{Cl}$ \\
\hline Overall & 1.43 & (1.38 to 1.48 ) & 0.49 & (0.31 to 0.67 ) & 2.68 & (2.65 to 2.70 ) & 0.63 & (0.54 to 0.72 ) \\
\hline \multicolumn{9}{|l|}{ Gender } \\
\hline Men & 1.05 & (0.75 to 1.35 ) & 0.47 & (0.21 to 0.74 ) & 2.23 & (2.03 to 2.43 ) & 0.68 & (0.57 to 0.79 ) \\
\hline Women & 1.68 & (1.37 to 1.99$)$ & 0.55 & (0.12 to 0.97$)$ & 2.99 & (2.78 to 3.19 ) & 0.58 & (0.47 to 0.69$)$ \\
\hline \multicolumn{9}{|l|}{ Race } \\
\hline White & 1.38 & (1.13 to 1.63 ) & 0.53 & (0.26 to 0.79 ) & 2.62 & (2.43 to 2.80 ) & 0.67 & (0.58 to 0.77 ) \\
\hline Black & 1.10 & (0.78 to 1.41$)$ & 0.31 & $(-0.22$ to 0.84$)$ & 2.59 & (2.37 to 2.80 ) & 0.44 & (0.25 to 0.63$)$ \\
\hline Other & 1.52 & (0.99 to 2.05 ) & -0.03 & $(-1.21$ to 1.14$)$ & 2.62 & (2.32 to 2.92 ) & 0.51 & (0.14 to 0.88$)$ \\
\hline \multicolumn{9}{|l|}{ Education } \\
\hline College and above & 1.28 & (0.96 to 1.59 ) & 0.56 & (0.24 to 0.89$)$ & 2.35 & (2.13 to 2.57 ) & 0.76 & (0.60 to 0.91$)$ \\
\hline High school & 1.37 & (1.06 to 1.67$)$ & 0.50 & (0.18 to 0.83 ) & 2.59 & (2.38 to 2.79 ) & 0.69 & (0.58 to 0.80$)$ \\
\hline Less than high school & 1.45 & (1.13 to 1.77$)$ & 0.40 & $(-0.04$ to 0.83$)$ & 2.91 & (2.71 to 3.12 ) & 0.50 & (0.37 to 0.63$)$ \\
\hline \multicolumn{9}{|c|}{ Non-housing financial wealth } \\
\hline Highest tertile & 1.18 & (0.87 to 1.50$)$ & 0.47 & (0.17 to 0.77 ) & 2.39 & (2.19 to 2.60 ) & 0.72 & (0.61 to 0.83$)$ \\
\hline Middle tertile & 1.35 & (1.05 to 1.64 ) & 0.48 & ( 0.15 to 0.80 ) & 2.53 & (2.33 to 2.74 ) & 0.63 & (0.52 to 0.74$)$ \\
\hline Lowest tertile & 1.57 & (1.27 to 1.86 ) & 0.54 & (0.16 to 0.91 ) & 2.91 & (2.71 to 3.11 ) & 0.54 & (0.41 to 0.67$)$ \\
\hline
\end{tabular}

Models are adjusted for age, sex, race, education, non-housing wealth, health insurance coverage, Body Mass Index, smoking, physical activity, number of diseases and study cohort.

${ }^{*}$ Refers to adjusted population mean in number of physical functioning difficulties.

tRefers to increase in number of physical functioning difficulties by every 10 years.

Table 2 shows the average level and 10 years change in number of physical functioning difficulties in different sociodemographic subgroups. On average, the number of physical functioning difficulties was 1.4 when in full-time work and 2.7 in retirement. The number of physical functioning difficulties was higher in women, and those with low education and in the lowest tertile of non-housing financial wealth both among the full-time workers and retirees. Among retirees, black participants, low education and low non-housing wealth were associated with lower increase in physical functioning difficulties. There were no differences by sociodemographic factors among full-time workers.

Table 3 Average level and 10-year change at population level in number of physical functioning difficulties according to number of chronic diseases and lifestyle factors

\begin{tabular}{|c|c|c|c|c|c|c|c|c|}
\hline & \multicolumn{4}{|l|}{ Full-time work } & \multicolumn{4}{|l|}{ Retired } \\
\hline & Average level* & $95 \% \mathrm{Cl}$ & 10-year changet & $95 \% \mathrm{Cl}$ & Average level* & $95 \% \mathrm{Cl}$ & 10-year changet & $95 \% \mathrm{Cl}$ \\
\hline \multicolumn{9}{|c|}{ Number of chronic diseases } \\
\hline 0 & 0.66 & (0.38 to 0.94 ) & 0.42 & $(-0.08$ to 0.93$)$ & 1.71 & (1.50 to 1.91$)$ & 0.60 & (0.48 to 0.72$)$ \\
\hline 1 & 1.25 & (0.95 to 1.54 ) & 0.52 & (0.20 to 0.84$)$ & 2.61 & (2.41 to 2.81 ) & 0.64 & (0.53 to 0.75$)$ \\
\hline 2 or more & 2.20 & (1.84 to 2.55$)$ & 0.50 & (0.23 to 0.77$)$ & 3.52 & (3.31 to 3.73 ) & 0.65 & (0.52 to 0.77 ) \\
\hline \multicolumn{9}{|c|}{ Number of lifestyle-related risks§ } \\
\hline 0 & 1.02 & (0.72 to 1.32 ) & 0.43 & (0.14 to 0.72$)$ & 2.07 & (1.86 to 2.27$)$ & 0.64 & ( 0.53 to 0.75$)$ \\
\hline 1 & 1.30 & (1.01 to 1.59$)$ & 0.55 & (0.23 to 0.86$)$ & 2.59 & (2.38 to 2.79 ) & 0.63 & (0.53 to 0.63$)$ \\
\hline 2 or more & 1.62 & (1.30 to 1.93$)$ & 0.55 & (0.09 to 0.55$)$ & 3.03 & (2.82 to 3.24$)$ & 0.59 & ( 0.45 to 0.73$)$ \\
\hline \multicolumn{9}{|c|}{ Individual lifestyle-related risks§ } \\
\hline \multicolumn{9}{|c|}{ Body Mass Index (BMI) } \\
\hline Normal weight & 1.03 & (0.73 to 1.33 ) & 0.24 & $(-0.05$ to 0.53$)$ & 2.37 & (2.17 to 2.57 ) & 0.65 & (0.54 to 0.77 ) \\
\hline Overweight & 1.32 & (1.02 to 1.62 ) & 0.61 & (0.31 to 0.92 ) & 2.50 & (2.30 to 271 ) & 0.60 & ( 0.49 to 0.71$)$ \\
\hline Obese & 1.75 & (1.43 to 2.07 ) & 0.59 & (0.12 to 1.06$)$ & 2.98 & (2.77 to 3.19 ) & 0.67 & (0.52 to 0.81$)$ \\
\hline \multicolumn{9}{|l|}{ Smoking } \\
\hline Never smoker & 1.31 & (1.01 to 1.62 ) & 0.39 & (0.04 to 0.75$)$ & 2.40 & (2.20 to 2.60 ) & 0.63 & (0.51 to 0.75$)$ \\
\hline Ex-smoker & 1.36 & (1.07 to 1.66$)$ & 0.57 & (0.26 to 0.88 ) & 2.59 & (2.38 to 2.79 ) & 0.66 & (0.55 to 0.77 ) \\
\hline Current smoker & 1.42 & (1.08 to 1.75$)$ & 0.46 & (0.01 to 0.91 ) & 2.83 & (2.61 to 3.06 ) & 0.53 & (0.34 to 0.72 ) \\
\hline \multicolumn{9}{|l|}{ Physical activity } \\
\hline Physically active & 1.23 & (0.94 to 1.52 ) & 0.46 & (0.18 to 0.74 ) & 2.30 & (2.10 to 2.50$)$ & 0.66 & ( 0.55 to 0.76$)$ \\
\hline Low physical activity & 1.48 & (1.18 to 1.77 ) & 0.52 & (0.21 to 0.84 ) & 2.81 & (2.61 to 3.01 ) & 0.62 & (0.52 to 0.72 ) \\
\hline
\end{tabular}



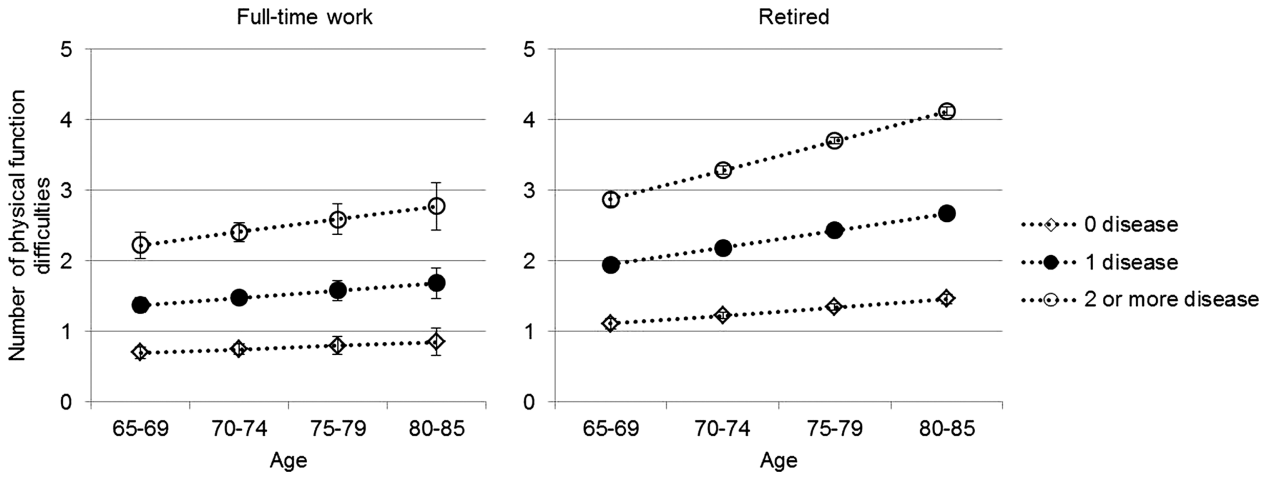

Figure 2 Number of physical functioning difficulties according to age, working status and number of diseases.

Table 3 shows the adjusted average level and 10-year change in number of physical functioning difficulties based on lifestyle-related risks and chronic conditions. On average, the number of physical functioning difficulties was higher in subjects with more chronic diseases and lifestyle-related risks both while in full-time work and retirement. As long as participants were in full-time work, there was a small, but non-significant increase in physical functioning difficulties with increasing age and number of chronic diseases compared with those with no disease. Among retirees, mobility difficulties increased with increasing number of chronic diseases among the subjects (figure 2).

Number of physical functioning difficulties increased with age and number of lifestyle-related risk factors both in full-time work and retirement. However, during retirement, the number of difficulties and rate of increase was on a higher level than in work (figure 3). Among the three lifestyle-related risk factors, obesity was associated with greater number of physical functioning difficulties in full-time work and retirement, while the physical functioning trajectory was not dependent on smoking status or physical activity.

Finally, a sensitivity analysis was conducted by including only those who remained in the same work status (ie, full-time work or retired) during the entire follow-up. The results remained very similar for the retirees, but in the full-time workers the mean estimates for number of physical functioning difficulties were slightly lower compared with the main analysis (see online Supplementary table).

\section{DISCUSSION}

Based on a large longitudinal population-based study from 1992 to 2010 , we observed greater increase in physical functioning difficulties during retirement than while still in full-time work. Even the absence of chronic diseases and lifestyle-related risks did not completely explain the differences in physical functioning among full-time workers and retirees. It was also found that among full-time workers and retirees, there was disparity in the development of physical functioning difficulties based on their disease status and lifestyle-related risk factors.

Unlike the previous studies in this field, ${ }^{7-9} 1219$ the HRS data allowed us to examine physical functioning trajectories after the age of 65 and see whether those extending their working life are doing better or worse in terms of their functioning. Our results suggest that work may have positive effects on functioning even into very old age. This is partly in contrast to what Jokela and colleagues ${ }^{12}$ reported based on the Whitehall II study, in which they found that statutory and voluntary early retirement was associated with better physical functioning. However, the discrepancy may result from age differences of the study population as well as different retirement systems in the UK and USA.

Potential explanations for our findings include the fact that full-time workers are more likely to keep their level of physical activity through daily work which may help to maintain older worker's functioning. ${ }^{20}$ In addition, work provides structure in life, social relationship as well as support and satisfaction of accomplishment. Previous studies have shown that social participation, social support and social capital are associated with better physical functioning. ${ }^{21} 22$ Subjects still in the working life may also enjoy better access to healthcare services via stable income. Unfortunately, explanations involved with these mediators cannot be tested in the current study because corresponding measures were not available. However, further research is needed to examine the pathways linking extended working life with better physical functioning.

Zhan and colleagues ${ }^{23}$ have discussed the different motives older people may have to extend their working life. Some people may continue working because of financial pressures. ${ }^{24}$ In this situation, participation in working life may not necessarily facilitate employees' health, especially their mental health. On the other hand, some may want to continue working because they
Figure 3 Number of physical functioning difficulties according to age, working status and number of lifestyle-related risks.
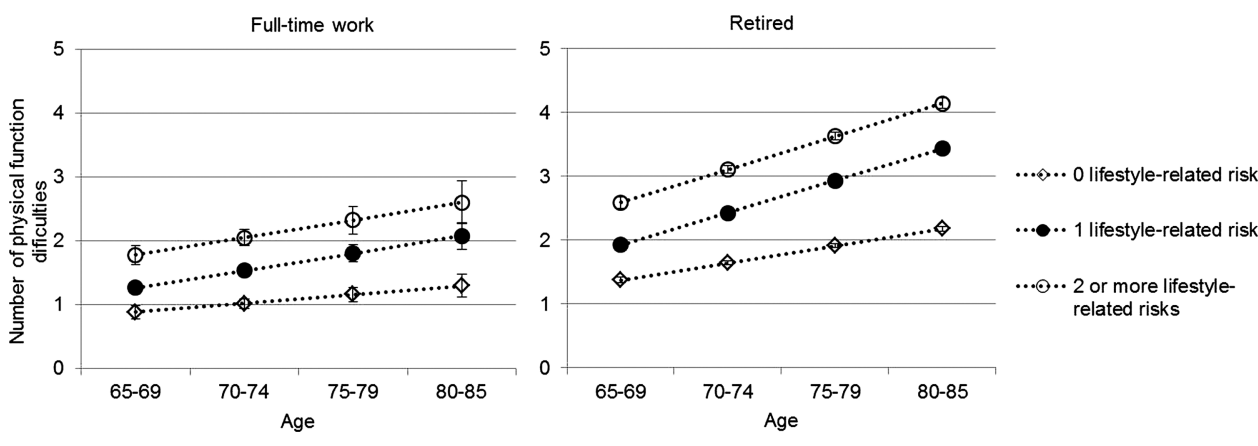
are interested in working with colleagues or contributing with their knowledge and skills. ${ }^{23}$ In this situation, the health and functioning are likely to be maintained. In addition to voluntarily extending working life, voluntary early retirement may also have favourable association with physical functioning, as was shown by Jokela and colleagues in the Whitehall II study. ${ }^{12}$ Unfortunately, no information about the voluntary/involuntary nature of extending working life was available in the public version of HRS.

It is of course evident that health is an important factor for older workers in making the decision whether to retire or continue working. Healthier people tend to continue working longer and retire later than those with poor health. ${ }^{24-26}$ Based on our findings, participants aged 80-85 years who were still working had almost the same level of physical difficulties as retirees aged 65-69 years. We tried to address the potential health selection into retirement by stratifying the analysis by disease status. We observed that among those with no selfreported chronic diseases, the number of physical functioning difficulties was at a much lower level in full-time workers compared with retired participants. This result suggests that even the absence of chronic diseases did not completely explain the differences in physical functioning among full-time workers and retirees. In addition, our sensitivity analysis showed that those who remained in full-time work had less physical functioning difficulties than those who retired during the follow-up, suggesting that health and physical functioning plays an important role whether to remain in the working life or whether to retire. Finally, it was also found that more men continued working after the age of 65 and they also had higher education, which may partly explain better physical functioning among the fulltime workers.

The main strengths of the study include prospective longitudinal design with biennial information on physical functioning covering on average 6 years, in some cases even 18 years, after the age of 65 years. The results can be generalised to the US adult population due to the nationally representative sample. Although the absolute difference between full-time workers and retirees does not seem very large, at a population level the differences may be meaningful. The limitations of the study also need to be discussed. First, to increase contrast we only compared two distinct periods in life: in full-time work and retirement, but in real life part-time work is increasingly common before retiring full-time. Moreover, the transition from work to retirement is not random in relation to physical functioning. This implies that the older the age group the greater is health-related selection to stay in work, affecting the divergence in the trajectories of physical functioning in full-time work compared with retirement. Although our findings suggest that extending working life may help to maintain physical functioning even among the very old adults, we do not know the extent to which selection to retirement as a function of emerging difficulties in physical functioning affect the results. Second, this study was based on self-reported measures of physical functioning and health status. Replication using objective physical performance measures would alleviate concerns regarding potential self-reported bias. On the other hand, self-reports provide us valuable information about an individual's own perception of his/her functioning in the living environment. ${ }^{4}$ Third, this study focused on working status (ie, full-time work and retired), but did not take into account work characteristics such as physical or mental strain at work.

To conclude, data from a population-based sample of US adults aged 65 years and older indicate that difficulties in physical functioning are more common among retirees than among full-time workers aged 65 years or older and the difference is not explained by chronic diseases and lifestyle-related risks. Maintaining and promoting good physical functioning may enable older workers extend their working careers.

\section{What is already known on this subject?}

- Previous studies report conflicting results regarding the health effects of retirement.

- Loss of physical functioning is a useful and early marker of declining health and also seriously threatens the independence and quality of life of older people.

- No previous study has examined how trajectories of physical functioning differ by working status among people aged 65 and older.

\section{What this study adds?}

- Physical functioning difficulties are more common among retirees than those who continue working after age of 65 years and the differences are not explained by absence of chronic diseases or lifestyle-related risks.

- Maintaining and promoting good physical functioning may enable older workers to extend their working careers.

\section{Author affiliations}

${ }^{1}$ Department of Public Health, University of Turku, Turku, Finland ${ }^{2}$ Department of Health, Functional Capacity and Welfare, National Institute for Health and Welfare (THL), Helsinki, Finland

${ }^{3}$ Stress Research Institute, Stockholm University, Stockholm, Sweden

${ }^{4}$ Finnish Institute of Occupational Health, Helsinki, Finland

${ }^{5}$ Department of Psychology, University of Turku, Turku, Finland

${ }^{6}$ Department of Epidemiology and Public Health, University College London, London, UK

${ }^{7}$ Turku University Hospital, Turku, Finland

Contributors SS, HW, PS, MH and JV designed the study, SS and JP analysed the data. SS wrote the first version. SS, HW, PS, MH, JP, JH, MK and JV revised it critically and interpreted the data. All the authors have seen and approved the final version.

Funding This work was supported by the EU's Era-Age 2 programme (Academy of Finland (264 944) and the Swedish Research Council for Health, Working Life and Welfare (Forte, 2012-1661)). Sari Stenholm is also supported by the Academy of Finland (273 850). Jenny Head is supported by the Economic and Social Research Council (ES/K01 336X/1). Mika Kivimäki is also supported by the UK Medical Research Council (K013 351), the National Heart, Lung and Blood Institute (HL36310), the National Institute of Aging (AG034454), and a professorial fellowship from the Economic and Social Research Council. The funders had no role in study design, data collection and analysis, decision to publish, or preparation of the manuscript.

Competing interests None.

Ethics approval University of Michigan Institutional Review Board.

Provenance and peer review Not commissioned; externally peer reviewed.

\section{REFERENCES}

1 Social Security Administration. Retirement. 2009.

2 Guralnik JM, Ferrucci L, Pieper CF, et al. Lower Extremity Function and Subsequent Disability: Consistency Across Studies, Predictive Models, and Value of Gait Speed Alone Compared With the Short Physical Performance Battery. J Gerontol A Biol Sci Med Sci 2000;55A:M221-M31. 
3 Hirvensalo M, Rantanen T, Heikkinen E. Mobility Difficulties and Physical Activity as Predictors of Mortality and Loss of Independence in the Community-Living Older Population. J Am Geriatr Soc 2000;48:493-8.

4 Guralnik JM, Simonsick EM, Ferrucci L, et al. A Short Physical Performance Battery Assessing Lower Extremity Function: Association With Self-Reported Disability and Prediction of Mortality and Nursing Home Admission. J Gerontol 1994;49:M85-94.

5 Stuck AE, Walthert JM, Nikolaus T, et al. Risk factors for functional status decline in community-living elderly people: a systematic literature review. Soc Sci Med 1999;48:445-69.

6 Brown CJ, Flood KL. Mobility limitation in the older patient: A clinical review. JAMA 2013;310:1168-77.

7 Hinterlong JE, Morrow-Howell N, Rozario PA. Productive Engagement and Late Life Physical and Mental Health: Findings from a Nationally Representative Panel Study. Res Aging 2007;29:348-70.

8 Luoh MC, Herzog AR. Individual consequences of volunteer and paid work in old age: health and mortality. J Health Soc Behav 2002;43:490-509.

9 Wickrama KK, O'Neal CW, Kwag KH, et al. Is working later in life good or bad for health? An investigation of multiple health outcomes. J Gerontol B Psychol Sci Soc Sci 2013;68:807-15.

10 Westerlund $\mathrm{H}$, Kivimäki M, Singh-Manoux $\mathrm{A}$, et al. Self-rated health before and after retirement in France (GAZEL): a cohort study. Lancet 2009;374:1889-96.

11 Westerlund $\mathrm{H}$, Vahtera J, Ferrie JE, et al. Effect of retirement on major chronic conditions and fatigue: French GAZEL occupational cohort study. BMJ 2010;341: c6149.

12 Jokela M, Ferrie JE, Gimeno D, et al. From midlife to early old age: health trajectories associated with retirement. Epidemiology 2010;21:284-90.

13 Growing older in America: The Health and Retirement Study. 2013.

14 Wahrendorf M, Reinhardt JD, Siegrist J. Relationships of disability with age among adults aged 50 to 85: evidence from the United States, England and continental europe. PLoS One 2013;8:e71893.
15 Avendano M, Glymour MM, Banks J, et al. Health disadvantage in US adults aged 50 to 74 years: a comparison of the health of rich and poor Americans with that of Europeans. Am J Public Health 2009:99:540-8.

16 Nagi SZ. A study in the evaluation of disability and rehabilitation potential: Concepts, methods, and procedures. Am J Public Health 1964:54:1568-79.

17 Zeger SL, Liang K-Y. Longitudinal data analysis for discrete and continuous outcomes. Biometrics 1986;42:121-30.

18 Diggle PJ, Liang KY, Zeger SL. Analysis of Longitudinal Data. Oxford, UK: Oxford University Press, 1994.

19 Mein $G$, Martikainen $\mathrm{P}$, Hemingway $\mathrm{H}$, et al. Is retirement good or bad for mental and physical health functioning? Whitehall II longitudinal study of civil servants. J Epidemiol Community Health 2003;57:46-9.

20 Jex SM, Wang M, Zarubin A. Aging and occupational health. In: Shultz KS, Adams GA. eds. Aging and work in the 21st century. Mahwah, NJ: Erlbaum, 2007:199-223.

21 Ichida $\mathrm{Y}$, Hirai $\mathrm{H}$, Kondo $\mathrm{K}$, et al. Does social participation improve self-rated health in the older population? A quasi-experimental intervention study. Soc Sci Med 2013:94:83-90.

22 Aida J, Kondo K, Kawachi I, et al. Does social capital affect the incidence of functional disability in older Japanese? A prospective population-based cohort study. J Epidemiol Community Health 2013;67:42-7.

23 Zhan Y, Wang M, Liu S, et al. Bridge employment and retirees' health a longitudinal investigation. J Occup Health Psychol 2009;14:374-89.

24 Mein G, Martikainen P, Stansfeld SA, et al. Predictors of early retirement in British civil servants. Age Ageing 2000;29:529-36.

25 Taylor MA, Shore LM. Predictors of planned retirement age: an application of Beehr's model. Psychol Aging 1995;10:76-83.

26 Rice NE, Lang IA, Henley W, et al. Common health predictors of early retirement: findings from the English Longitudinal Study of Ageing. Age Ageing 2011:40:54-61 